\title{
Effect of change in position of particle dampers on wind turbine blade for vibration suppression
}

\author{
Santosh R. Sandanshiv ${ }^{1}$, Umesh S. Chavan ${ }^{2}$ \\ ${ }^{1}$ Genba Sopanrao Moze College of Engineering, Pune, India \\ ${ }^{2}$ Vishwakarma Institute of Technology, Pune, India \\ ${ }^{1}$ Corresponding author \\ E-mail: ${ }^{1}$ santoshsandanshiv@yahoo.com, ${ }^{2}$ umesh.chavan@vit.edu \\ Received 25 July 2019; accepted 2 August 2019 \\ DOI https://doi.org/10.21595/vp.2019.20921
}

Check for updates

Copyright $(2019$ Santosh R. Sandanshiv, et al. This is an open access article distributed under the Creative Commons Attribution License, which permits unrestricted use, distribution, and reproduction in any medium, provided the original work is properly cited.

\begin{abstract}
Wind turbine energy minimizes due to vibration of blade. In this research we focus on vibration suppression by using particle damping technique. Containers are used for fill the particles and mounted on the blade. As vibration of blade increases, it increases the movement of containers along with particles this brings particle to particle and particle to container wall collision takes place which results to energy loss. In this study we use four different positions for mounting containers, firstly on all four different positions we mount containers simultaneously and take three readings for three different ball sizes respectively, keeping $50 \%$ fill constant in all readings. Then we reduce one container among four and take the readings. Repeat this procedure up to single container. Compare with damping results with without damping results and finding out optimum locations for mounting of dampers.
\end{abstract}

Keywords: vibration, particle damping, wind turbine blade, energy loss.

\section{Introduction}

In wind energy power generation, if vibrations of the blade are high then it adversely effect on electricity generation [1]. Edgewise vibration and flapwise vibrations were the two main modes of vibration in blade [2]. Edgewise vibration is the main concern in this work. Structural vibration had been control by three methods namely active, semi active and passive control according to Dapeng [3]. Krenk [4] introduced active struts mounted near the blade root. Fitzgerald introduced edgewise vibration mitigation by using active tuned mass damper [5]. According to Box [6] active tendons was inserted inside blade for vibration control. Box [7] was introducing roller damper in blade. The new concept as tuned liquid column damper (TLCD) for blade vibration reduction, passive damping was used by Colwell [8] and Murtagh [9] in wind turbine tower for control of vibrations.

In this paper particle damping technique is used to check the effect of different parameters on $1 \mathrm{~kW}$ wind turbine blade for vibration suppression. Three parameters are used such as particle size variation, change in position and change in percentage fill. At this moment it is not possible to make pocket inside the blade for inserting balls. But for checking the effect we attach external container on blade.

\section{Experimental set up}

Electrodynamic shaker (EEV 060) having force rating of $600 \mathrm{Kgf}$ is use for generating frequency in the range of $10 \mathrm{~Hz}$ to $2000 \mathrm{~Hz}$ and Acceleration is consider for the first two modes. We consider $1 \mathrm{Kw}$ wind turbine blade for testing which is mounted at the root location and hermetically sealed type piezo electric accelerometer is mounted at the position of $600 \mathrm{~mm}$ randomly considering the maximum displacement location. Output of accelerometer is connected to single channel, digital vibration controller (EESC - 04), generating low electric signals. These electric signals amplify with power amplifier from the vibration controller to a proportionally high voltage and high current output. Acceleration range is kept as $8 \mathrm{~g}$ and frequency range up to 
$2000 \mathrm{~Hz}$. Materials and different parameters are explained as follows.

\subsection{Parameters for testing}

\subsubsection{Ball size}

Three different particle sizes are used as $3 \mathrm{~mm}, 5 \mathrm{~mm}$ and $9 \mathrm{~mm}$ for effect of vibration suppression.

\subsubsection{Container position on blade}

Total four positions taken for the testing as $300 \mathrm{~mm}, 600 \mathrm{~mm}, 900 \mathrm{~mm}$ and $1200 \mathrm{~mm}$.

\subsection{Materials}

(a) Particle: Testing of particle is done by Wet Method: ALS:SOP:05-TM 503, REST by IS 228:2010 for particle damping having chemical composition of $0.010 \% \mathrm{Mo}, 0.050 \% \mathrm{Ni}, 0.98 \%$ C, $0.33 \% \mathrm{Mn}, 0.25 \% \mathrm{Si}, 0.010 \% \mathrm{~S}, 0.012 \% \mathrm{P}, 1.40 \% \mathrm{Cr}$.

(b) Container: Container is made with Poly-propylene (PP) material, tested by method of ASTM D-792, D-297 and IS 13360.

(c) Blade: Glass fibre blade having length of $1525 \mathrm{~mm}$.

Fig. 1(a) and (b) shows spring mass diagram for ball-wall and ball-ball collisions, where, $K_{N}$, $K_{S}, C_{N}, C_{S}$ are stiffness's and damping constants.

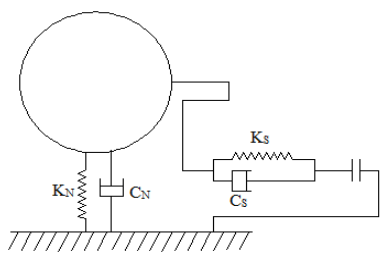

a)

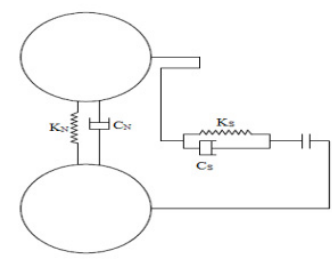

b)

Fig. 1. a) Ball-wall spring mass diagram, b) ball-ball spring mass diagram

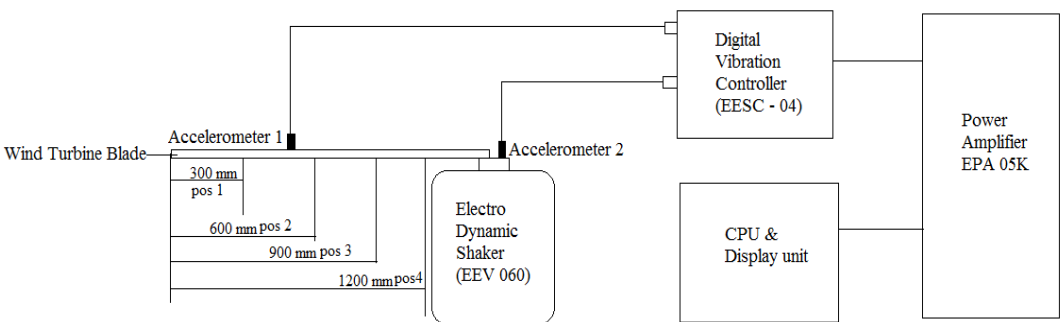

Fig. 2. Block diagram of experimental set up

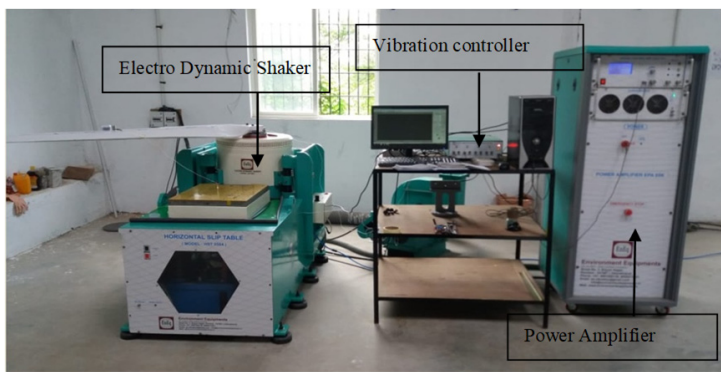

Fig. 3. Actual diagram of experimental set up 
Fig. 2 shows block diagram and Fig. 3 shows Actual experimental set up. Fig. 4 shows four different mounting conditions of containers as single, 2 positions, 3 positions and 4 positions mounting.
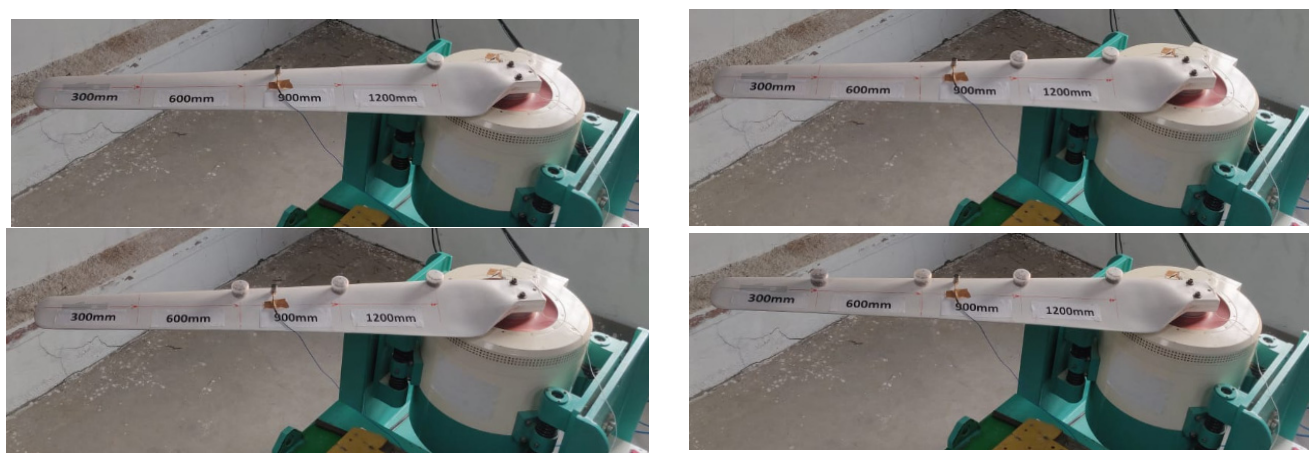

Fig. 4. Containers at different positions (single, two, three, four containers respectively)

\section{Result and discussion}

All results are plotted as acceleration in gravity $(\mathrm{g})$ versus frequency $(\mathrm{Hz})$ for without damping and with damping conditions.

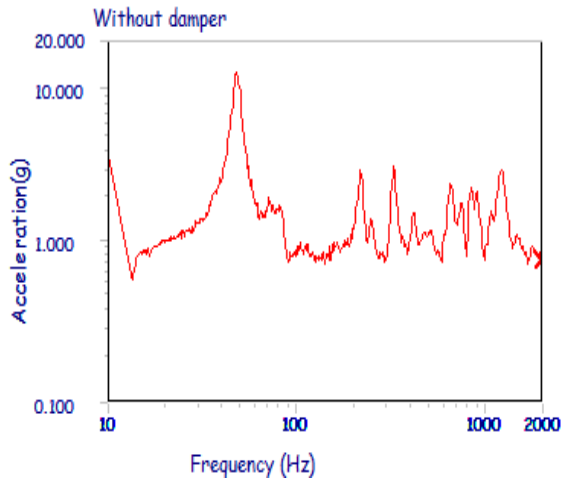

Fig. 5. Without damping

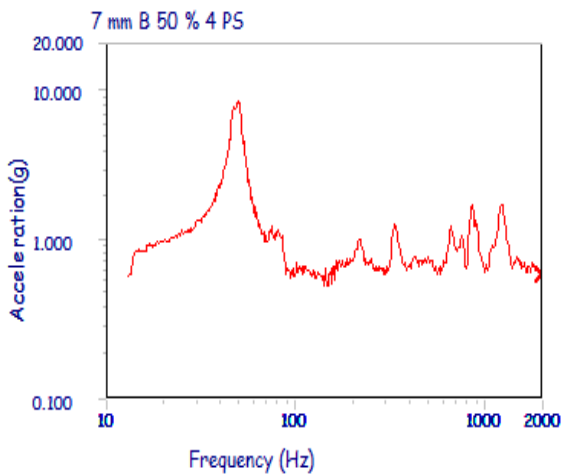

Fig. 7. Four position damper, $7 \mathrm{~mm}$ ball, $50 \%$ fill

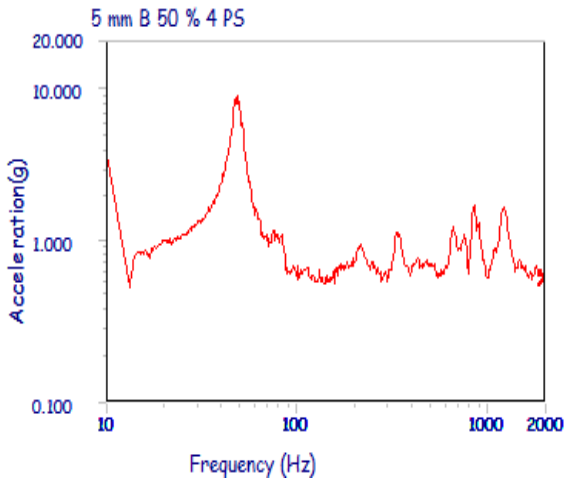

Fig. 6. Four position damper, $5 \mathrm{~mm}$ ball, $50 \%$ fill

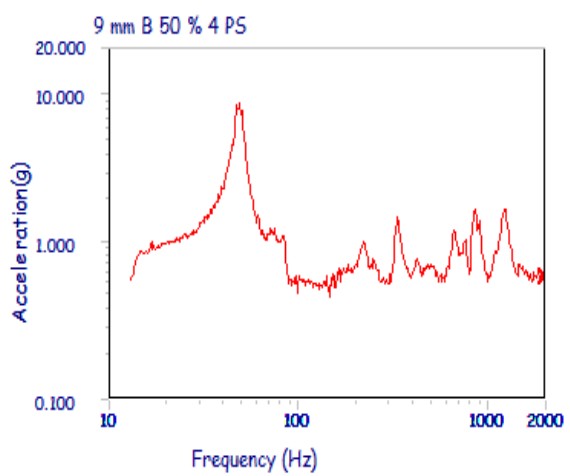

Fig. 8. Four position damper, $9 \mathrm{~mm}$ ball, $50 \%$ fill

Fig. 5 show with damping results as $12.895 \mathrm{~g}$ and $2.753 \mathrm{~g}$ for $1 \mathrm{st}$ and 2 nd modes respectively. All with damping results are compared with without damping and finding out the optical conditions for mounting dampers. All containers are fill with $50 \%$ particles, and taking readings 
for three different ball sizes as $5 \mathrm{~mm}, 7 \mathrm{~mm}$ and $9 \mathrm{~mm}$ respectively.

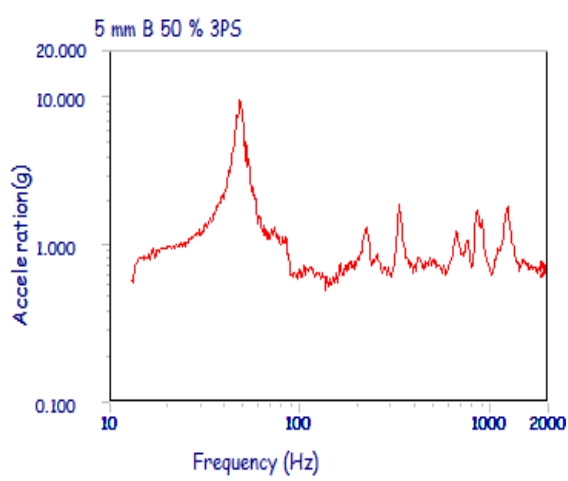

Fig. 9. Three position damper, $5 \mathrm{~mm}$ ball, $50 \%$ fill

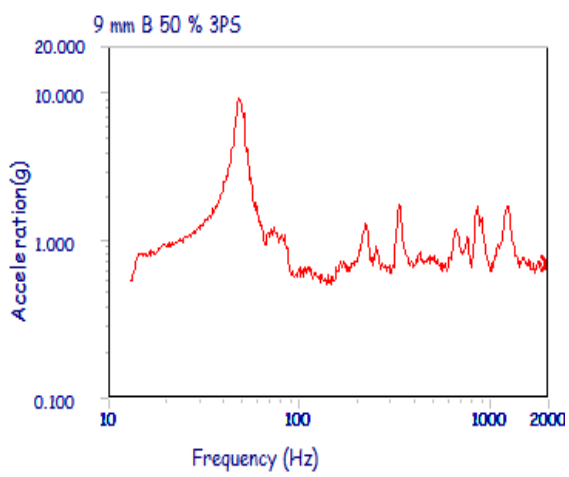

Fig. 11. Three position damper, $9 \mathrm{~mm}$ ball, $50 \%$ fill

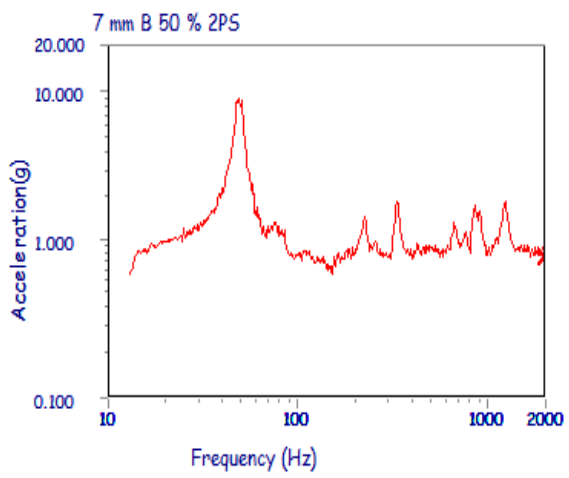

Fig. 13. Two position damper, $7 \mathrm{~mm}$ ball, $50 \%$ fill

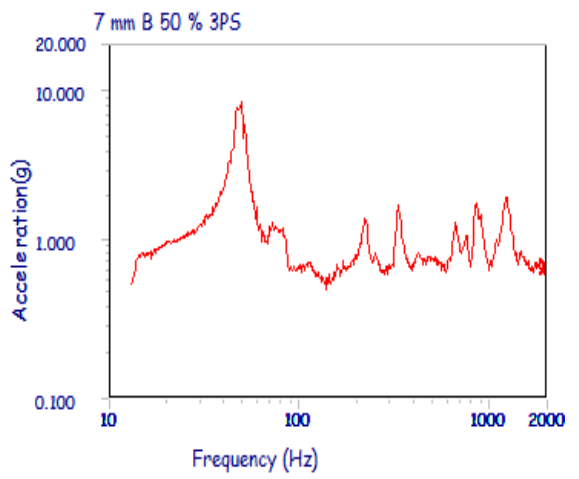

Fig. 10. Three position damper, $7 \mathrm{~mm}$ ball, $50 \%$ fill

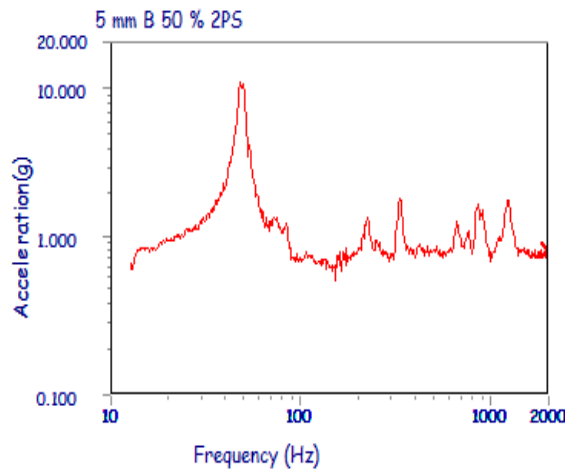

Fig. 12. Two position damper, $5 \mathrm{~mm}$ ball, $50 \%$ fill

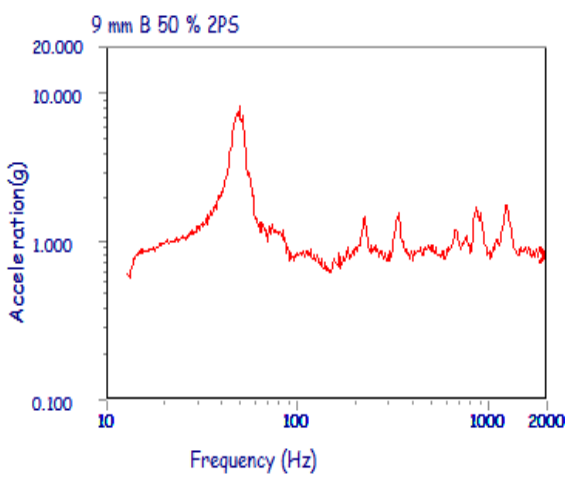

Fig. 14. Two position damper, $9 \mathrm{~mm}$ ball, $50 \%$ fill

Table 1 gives results of containers mounting at 4 position, 3 position, 2 position, 1 position and without damping conditions. Fig. 6-8 shows graphs for 4 position mount, Figs. 9-11 gives graphs for 3 position mount , 5, 7 and $9 \mathrm{~mm}$ ball sizes graphs. Figs. 12-14 shows graphs for 2 position mount and Fig. 15-17 shows graphs for single position mount.

Table 1 shows that in 4 position mount $7 \mathrm{~mm}$ ball gives optimum results as $8.565 \mathrm{~g}$ and $1.830 \mathrm{~g}$ acceleration for 1 st and 2 nd modes. All results are compared with without damping results as in 1 st mode $12.895 \mathrm{~g}$ is very large acceleration as compared to 4 position damping and in second mode $2.753 \mathrm{~g}$ is also high acceleration value. In 3 position and single position also $7 \mathrm{~mm}$ ball size gives optimum results. But, in case of 2 position mount $9 \mathrm{~mm}$ ball size gives optimum result as 
shown in Table 1. Same results are shown in cumulative result graph.

Table 1. Testing results for different positions

\begin{tabular}{|c|c|c|c|c|c|c|}
\hline \multirow{2}{*}{ Position of damper } & \multicolumn{7}{|c|}{ Particle (Ball) size } \\
\cline { 2 - 7 } & \multicolumn{2}{|c|}{$5 \mathrm{~mm}$} & \multicolumn{2}{c|}{ 7 mm } & \multicolumn{2}{c|}{ mm } \\
\cline { 2 - 7 } & 1st mode & 2nd mode & 1st mode & 2nd mode & 1st mode & 2nd mode \\
\hline 4 Position damping & 9.068 & 1.847 & 8.565 & 1.830 & 8.741 & 1.796 \\
\hline 3 Position damping & 9.549 & 1.975 & 8.157 & 2.033 & 9.452 & 1.892 \\
\hline 2 Position damping & 11.025 & 1.922 & 9.065 & 1.928 & 8.274 & 1.898 \\
\hline 1 Position damping & 11.251 & 1.983 & 9.299 & 1.951 & 10.774 & 1.874 \\
\hline Without damping & \multicolumn{7}{|c|}{ 1st Mode: 12.895, 2nd Mode: 2.753} \\
\hline
\end{tabular}
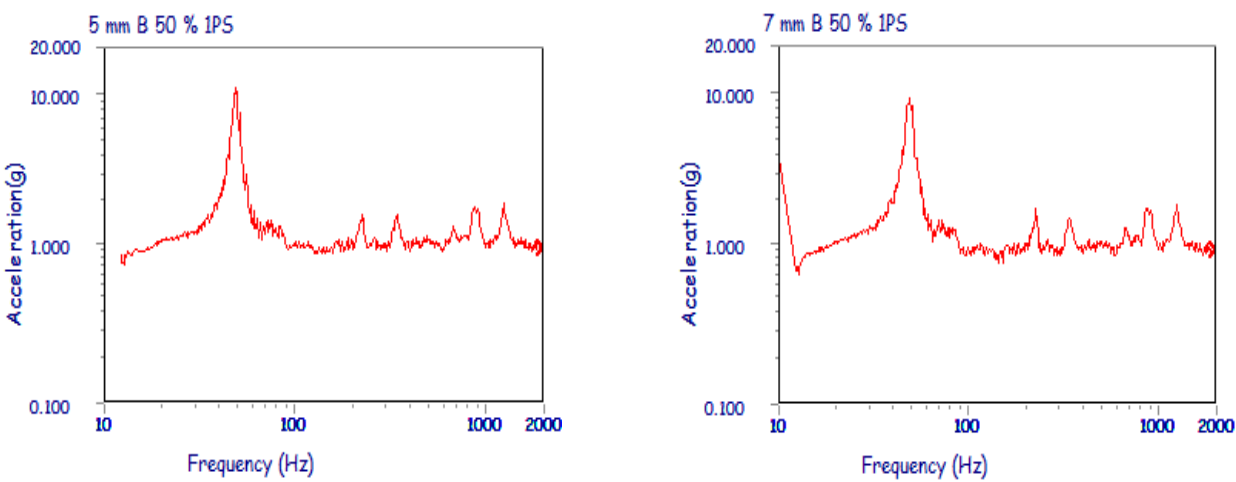

Fig. 15. Single position damper, $5 \mathrm{~mm}$ ball, $50 \%$ fill Fig. 16. Single position damper, $7 \mathrm{~mm}$ ball, $50 \%$ fill

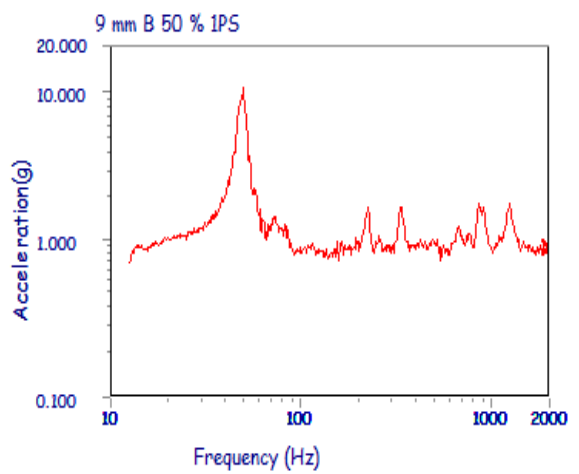

Fig. 17. Single position damper, $9 \mathrm{~mm}$ ball, $50 \%$ fill

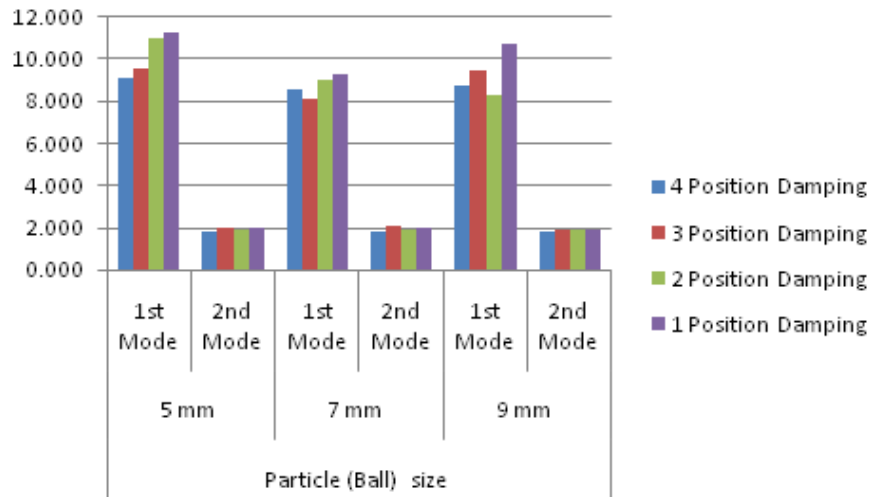

Fig. 18. Cumulative results for all positions and all particle sizes 


\section{Conclusions}

At $7 \mathrm{~mm}$ particle size we get optimum conditions for damper location as compare to $5 \mathrm{~mm}$ and $9 \mathrm{~mm}$ ball size. In overall results 3 position mounting with $7 \mathrm{~mm}$ particles and 2 position mount with $9 \mathrm{~mm}$ particles gives optimum conditions.

\section{References}

[1] Mina Ghassempour, Giuseppe Failla Vibration mitigation in offshore wind turbines via tuned mass damper. Engineering Structures, Vol. 183, 2019, p. 610-636.

[2] Thomsen K., Petersen J. T., Nim E., Øye S., Petersen B. A method for determination of damping for edgewise blade vibrations. Wind Energy, Vol. 3, Issue 4, 2000, p. 233-246.

[3] Qiu Dapeng, Chen Jianyun Dynamic responses and damage forms analysis of underground large scale frame structures under oblique SV seismic waves. Soil Dynamics and Earthquake Engineering, Vol. 117, 2019, p. 216-220.

[4] Krenk S., Svendsen M. N., Høgsberg J. Resonant vibration control of three-bladed wind turbine rotors. AIAA Journal, Vol. 50, Issue 1, 2012, p. 148-161.

[5] Fitzgerald B., Basu B., Nielsen S. R. K. Active tuned mass dampers for control of in-plane vibrations of wind turbine blades. Structural Control and Health Monitoring, Vol. 20, Issue 12, 2013, p. 1377-1396.

[6] George Box E. P., Norman Draper R. Empirical Model Building and Response Surfaces. John Wiley and Sons, New York, 1987.

[7] George Box E. P., Norman Draper R. Response Surfaces, Mixtures, and Ridge Analysis. Second Edition, John Wiley and Sons, Hoboken, New Jersey, USA.

[8] Colwell S., Basu B. Tuned liquid column dampers in offshore wind turbines for structural control. Engineering Structures, Vol. 31, Issue 2, 2009, p. 358-368.

[9] Murtagh P. J., Ghosh A., Basu B., Broderick B. M. Passive control of wind turbine vibrations including blade/tower interaction and rotationally sampled turbulence. Wind Energy, Vol. 11, Issue 4, 2007, https://doi.org/10.1002/we.249. 